\title{
IQTISHODUNA
}

Vol. 16 (2), 2020

P-ISSN: 1829-524X, E-ISSN: 2614-3437

\section{Membangun Hubungan Berkelanjutan Sektor UMKM dan Perbankan}

\author{
Basir. $\mathbf{S}^{1^{*}}$, Maretha Ika Prajawati ${ }^{2}$ \\ Sekolah Kajian Stratejik dan Global, Universitas Indonesia, Salemba- \\ Jakarta \\ UIN Maulana Malik Ibrahim Malang, Indonesia
}

*Corresponding Author:

E-mail: basir@ui.ac.id

\begin{abstract}
SMEs hope that their relationship with banks will provide them with ease in accessing capital and financing accordingly, with reasonable costs and conditions, where they expect a mutually beneficial and sustainable relationship in the future. The loyalty of SMEs in using banking services, the length of their relationship and reciprocal relationship shows that SMEs benefit from this relationship. One key element in their relationship is mutual trust. The results of the research show that trust affects effective commitment (affective commitment). Social bonding to affective commitment has a positive and significant effect on affective commitment. Affective commitment has a positive impact on behavioral intention. Attractive alternatives in their role of affective commitment and behavioral intention show that the variable attractive of alternative can strengthen the relationship of affective commitment and behavioral intention.
\end{abstract}

Keywords: trust, affective commitment, behavioral intention, attractive of alternative

\begin{abstract}
Abstrak: UMKM berharap hubungannya dengan bank akan memberikan mereka kemudahan dalam mengkases permodalan dan pembiayaan yang sesuai, dengan biaya dan persyaratan yang wajar, dimana mereka berharap hubungan yang saling menguntungkan dan hubungan yeng berkelanjutan di masa depan. Kesetiaan UKM dalam menggunakan layanan perbankan, lamanya hubungan keduanya dan hubungan timbal balik menunjukkan bahwa UKM memperoleh manfaat dari hubungan ini. Salah satu elemen kunci dalam hubungan keduanya adalah mutual trust. Hasil penelitian menunjukkan menujukkan bahwa kepercayaan (trust) berpengaruh terhadap komitmen efektif (affective commitment). Ikatan sosial (social bonding) terhadap affective commitment berpengaruh positif dan signifikan terhadap affective commitment. Affective commitment berpengaruh positif terhadap behavioral intention. Attractive of alternative dalam perannya terhadap affective commitment dan Niat berperilaku (behavioral intention), menunjukan bahwa variabel attractive of alternative mampu memperkuat hubungan yang dimiliki affective commitment dan behavioral intention.
\end{abstract}

Kata kunci: trust, affective commitment, behavioral intention, attractive of alternative 


\section{Cara mencitasi:}

Basir, S. dan Prajawati, M. I. (2020). Membangun Hubungan Berkelanjutan Sektor UMKM dan Perbankan. Iqtishoduna, 16 (2), 147-166.

\section{Pendahuluan}

Berkembangnya sektor UMKM di Kota Malang tidak terlepas dari dukungan pemerintah sebagai pembuat kebijakan serta perbankan sebagai pemberi modal. Dari sektor perbankan, kredit untuk sektor UMKM terus bertumbuh. Berdasarkan data Bank Indonesia Malang, nilai kredit untuk sektor UMKM di Kota Malang sebesar Rp 3,14 triliun tahun 2016, naik dari tahun sebelumnya sebesar $\mathrm{Rp} 2,94$ triliun pada tahun sebelumnya. Perbankan sebagai lembaga penghimpun dana dari masyarakat serta menyalurkan kembali kepada masyarakat, bank diharapkan dapat memenuhi kebutuhan akan permodalan bagi kegiatan kegiatan yang produktif, yaitu UMKM. Oleh karena itu dibutuhkan hubungan yang berkelanjutan antara keduanya. Hubungan yang bersifat dua sisi, kuat serta berkelanjutan antara sektor UMKM dengan pihak perbankan sangat penting dalam upaya mendukung volume bisnis yang signifikan dimana kedua belah pihak memiliki kesempatan yang sama dan saling menguntungkan serta sebagai mitra yang saling bekerja sama dengan memperhatikan prinsip saling mmebutuhkan, memperkuat dan saling membutuhkan.

Pengembangan UMKM harus mendapat perhatian lebih dari pemerintah sebagai pembuat kebijakan, selain itu masyarakat sebagai pengguna layanan juga perlu ikut serta dalam pengembangan UKM agar lebih mampu bersaing dengan pelaku ekonomi lainnya. Pembuat kebijakan, yaitu pemerintah dalam membuat kebijakan harus pro kepada UMKM agar secara kondusif dapat tumbuh dan berkembang. Pengembangan UMKM menghadapi dua masalah yang krusial, yaitu berhubungan dengan tersedianya modal yang mencukupi serta strategi pemasaran produk. Pada dasarnya modal merupakan hal yang perlu dan diutamakan dalam pengembangan UMKM. Oleh karenanya, selain pemerintah, pihak UMKM harus menjali kerjasana dan hubungan yang berkelanjutan dengan lembaga yang mampu membantu dalam segi permodalan. Lembaga tersebut tidak lain adalah perbankan. Perbankan menjadi salah satu pihak yang memiliki andil yang besar dalam pengembangan UMKM. Lembaga keuangan yang handal dan reliabel serta 
beorientasi pada layanan sangat penting bagi ekonomi serta memerankan peran yang penting bagi negara untuk mencapai pertumbuhan dan perkembangan ekonomi (Dogarawa, 2011).

Di dalam mendapatkan akses permodalan dari perbankan, UMKM seringkali mengalami kesulitan. Salah satu penyebabnya adalah tingkat suku bunga kredit yang tinggi dan disertai dengan adanya jaminan kebendaan (collateral minded) dalam memperoleh kredit yang terkadang sulit untuk mereka penuhi ditambah lagi dengan administrasi yang rumit. Definisi yang berbeda atas lembaga keuangan juga berdampak terhadap UMKM yang mengakibatkan mereka kesulitan dalam mendapatkan akses ke lambaga keuangan dalam berbagai hal secara operasional. Salah satunya adalah aspek pemasaran, ketidakpercayaan pada lembaha keuangan, tidak adanya aspek legalitas badan usaha, tidak memiliki laporan keuangan yang lengkap, tidak memiliki barangan jaminan, serta ketidakmampuan UMKM dalam membuat proposal pengajuan kredit yang sesuai dengan persyaratan perbankan (Lembaga Pemeringkat Kredit bagi UMKM, 2015).

Pembiayaan usaha kecil, mikro dan menengah (UKM) telah menarik banyak perhatian dalam beberapa tahun terakhir dan telah menjadi topik penting bagi para ekonom dan pembuat kebijakan yang bekerja dalam pengembangan keuangan dan ekonomi (de la Torre et al, 2010). Namun menjaga hubungan secara berkelanjutan antara keduanya belum banyak dilakukan penelitian. De la Torre et al. (2010) menggunakan istilah relationship lending yang menunjukkan hubungan antara sektor usaha kecil dan perbankan.

UMKM berharap hubungannya dengan bank akan memberikan mereka kemudahan dalam mengkases permodalan dan pembiayaan yang sesuai, dengan biaya dan persyaratan yang wajar, dimana mereka berharap hubungan yang saling menguntungkan dan hubungan yeng berkelanjutan di masa depan (Badulescu, 2012). Kesetiaan UKM dalam menggunakan layanan perbankan, lamanya hubungan keduanya dan hubungan timbal balik menunjukkan bahwa UKM memperoleh manfaat dari hubungan ini. Salah satu elemen kunci dalam hubungan keduanya adalah mutual trust. Mutual trust mengacu pada dua hal utama, pertama kepercayaan adalah kejujuran partner (trust is the partner honesty) yang mencakup kepercayaan dari pihak pertama kepada partnernya sebagai pihak kedua bahwa partnernya akan memenuhi janjinya, serrta kepercayaan adalah binovelen (trust is the partner benevolence) yaitu sampai sejauh mana pihak pertama percaya pada partnernya benar benar tertarik kepada kesejahteraan (welfare) pihak 
pertama (Sanzo et al., 2003).

UKM yang memiliki hubungan dengan secara berkelanjutan terbukti akan mampu meningkatkan akses ke pinjaman, walaupun pada saat yang sama mereka mengeluarkan biaya lebih tinggi untuk hutang mereka (Canovas dan Solano, 2010). Salah satu hal yang menarik adalah tentang bagaimana menganalisis cara alternatif memperkuat pinjaman yang menghasilkan efek yang lebih menguntungkan pada pembiayaan UKM. Hubungan antara perbankan dan kliennya tidak tergantung pada lamanya hubungan atau jumlah bank, tetapi lebih pada partisipasi bank dalam pembiayaan perusahaan, pada kapasitasnya untuk menghasilkan informasi, dan komitmennya untuk membantu UKM saat mengalami kesulitan keuangan (Canovas dan Solano, 2010). Dhliwayo (2014) mengungkapkan adanya kerja sama dengan pemangku kepentingan dalam mengembangkan sebuah kerangka inklusi keuangan untuk meningkatkan akses ke layanan permodalan oleh masyarakat yang terpinggirkan di daerah terpencil termasuk UKM dengan efisien, efektif dan sehat yang mampu menyediakan berbagai layanan keuangan yang digerakkan oleh permintaan termasuk persyaratan pembiayaan sektor UKM.

Beck et al. (2009) mengungkapkan untuk melayani UKM, bank mengembangkan berbagai jenis model bisnis baru, teknologi, serta sistem manajemen risiko. Pemberian pinjaman adalah sebagian kecil dari apa yang bank tawarkan kepada UKM, karena bank mencoba melayani UKM secara holistik melalui berbagai macam produk dan layanan. Model hubungan kemitraan stratgeis antara UMKM dengan perbankan syariah pernah dilakukan dalam penelitian Firmansyah dan Prajawati (2016). Hasil penelitiannya menunjukkan bahwa kemitraan yang dibangun berdasarkan pada aspek kepercayaan. Selain itu, UMKM yang memiliki kemampuan mengelola keuangan dengan baik, pengembangan UMKM dilakukan melalui kegiatan pelatihan secara bersama antara keduanya. Hal inilah yang menjadi pengembangan bagi perbankan syariah untuk mengembangkan pola kemitraan dengan UMKM.

Selain itu, Basir \& Prajawati (2016) dalam penelitiannya tentang model pengembangan ekonomi koperasi dan UMKM berbasis syariah di Kabupaten Malang menemukan bahwa strategi koperasi dan UMKM di Kabupaten Malang dalam membangun kemitraan antara koperasi, UMKM dan lembaga keuangan lainnya dilakukan berdasarkan pada asas manfaat saling menguntungkan atau dengan kata lain memperoleh kemaslahatan. UMKM dan koperasi perlu memperbaiki diri untuk dapat memenuhi kriteria 
feasible serta bankable yang meliputi aspek organisasi (legalitas usaha, prinsip 5C serta administrasi dan manajemen) serta aspek sumberdaya manusia.

Hubungan kemitraan antara perbankan dan UMKM dapat dilihat sebagai hubungan kerja sama usaha diantara berbagai pihak yang dibangun secara sinergis dan dilandasi oleh prinsip slaing membutuhkan, saling menghidupi, saling memperkuat serta saling menguntungkan. Hubungan jangka panjang antara sektor UMKM dan perbankan akan mampu menghasilkan efisiensi dan sinergi atas sumber daya yang dimiliki oleh pihak-pihak yang bermitra. Hubungan kemitraan akan memperkuat mekanisme pasar serta persaingan usaha yang efisien dan produktif. Dengan demikian, diharapkan kontribusi perbankan akan lebih maksimal pada semua jenis sektor UMKM. Dengan memperhatikan beberapa hal diatas berhubungan dengan membangun hubungan berkelanjutan antara sektor UMKM dengan pihak perbankan serta manfaat jangka panjangnya yang pada akhirnya akan mampu meningkatkan kinerja UMKM. Tujuan dalam penelitian ini adalah sebagai berikut: Menguji dan menganalis pengaruh trust terhadap affective commitment; Menguji dan menganalis pengaruh social bonding terhadap affective commitment; Menguji dan menganalisis pengaruh affective commitment terhadap behavioral intention. Serta menguji dan menganalis pengaruh hubungan antara affective commitment dengan behavioral intention.

\section{Kajian Pustaka}

\section{Relationship Marketing}

Shani \& Chalasani (1992) mengemukakan relationship marketing adalah upayamengembangkan hubungan yang berkesinambungan dengan pelanggan dalam hubungannya dengan serangkaian produk dan jasa. Gronroos (2000) memandang relationship marketing adalah upaya mengembangkan, mempertahankan, meningkatkan serta mengkomersialisasikan relasi pelanggan untuk mewujudkan tujuan semua pihak yang terlibat. Menurut Yang \& Wu (2007) relationship marketing seringkali didefinisikan sebagai kombinasi kebijakan, proses, dan strategi yang diterapkan organisasi menjadi satu kesatuan yang digunakan dalam proses interaksi dengan konsumen untuk menelusuri informasi konsumen.

Zeithmal dan Bitner (2013) mengacu pada klasifikasi relationship marketing berdasarkan pada level ikatan (bond) dengan konsumen sebagai

IQTISHODUNA Vol. 16 (2), $2020 \mid 151$

http://ejournal.uin-malang.ac.id/index.php/ekonomi 
dimensi pengukuran relationship marketing terdiri dari:

- $\quad$ Financial Bond. Financial Bonds merupakan usaha yang dilakukan untuk konsumen mellaui dorongan keuangan, menurunkan harga pada pembelian di dalam jumlah yang besar serta memberikan penurunan harga bagi konsumen yang telah menjadi pelanggan setia perusahaan dengan jumlah dan frekuensi hadiah, penjualan di dalam suatu paket serta penetapan harga yang cenderung stabil.

- $\quad$ Social Bond. Social bond adalah upaya bagi tenaga penjualan di dalam membangun hubungan jangka panjang yang dilakukan melalui hubungan antar pribadi dan sosial. Apabila konsumen dipandang sebagai "klien" yang tidak dikenal, hingga menjadi individu yang dapat diketahui kebutuhannya oleh tenaga penjualan, perusahaan akan berupaya mengetahui serta memahaminya melalui hubungan jangka panjang dan hubungan yang berkelanjutan.

- $\quad$ Structural Bond. Perusahaan menyediakan layanan ekstra dan bernilai bagi konsumen yang biasanya berbasis teknologi yang dirancang sebagai bagian dari keseluruhan sistem pelayanan untuk membantu konsumen dalam melakukan pembelian secara lebih efektif dan efisien.

\section{Definisi dan Dimensi Komitmen}

Komitmen mengacu pada hubungan pemasar-pelanggan yang didorong oleh persepsi pelanggan terhadap biaya switching yang tinggi (keuangan) (Menon dan O'Connor, 2007). Peran penting komitmen dalam mendukung hubungan pelanggan jangka panjang yang berkelanjutan sangat relevan dengan layanan perbankan (Aurier dan N'Goala, 2010; Fullerton, 2011). Kepercayaan memiliki efek pada komitmen yang positif dan signifikan (Coote et al., 2003). Arena perbankan dan jasa keuangan adalah rumah bagi risiko dan ketidakpastian, dan dengan demikian, kepercayaan yang dimiliki oleh pengguna layanan akan memberikan dorongan yang positif. Kepercayaan memiliki efek pada komitmen yang positif dan signifikan (Coote et al., 2003). Menurut Fullerton (2014) membedakan konsep komitmen menjadi :

- Komitmen afeksi, yaitu komitmen yang merujuk kepada pembagian nilai (shared values) dan kemurahan hati (benevolence).

- Komitmen kontinum, yaitu komitmen yang merujuk kepada pengorbanan dan ketergantungan.

- Komitmen normative, yaitu komitmen yang merujuk pada konstruk 
menyeluruh yang menjadi penyebab tumbuhnya rasa berbagi tanggung jawab

\section{Kepercayaan (trust) and Ikatan Sosial (social bonding)}

Peningkatan kepercayaan akan mengurangi persepsi pelanggan terhadap risiko dan memberikan tingkat jaminan yang lebih besar bahwa perilaku positif akan berasal dari penyedia layanan. Pengurangan risiko yang dirasakan dan meningkatkan kepercayaan pada penyedia layanan adalah motivator signifikan untuk menjaga hubungan di masa depan (Morgan danHunt, 1994). Ikatan sosial (social bonding) merupakan hubungan yang diciptakan melalui keterlibatan berkelanjutan antara perwakilan dari kedua organisasi (Venetis dan Ghauri, 2004). Tingkat keterikatan emosional yang nyata dalam hubungan semacam itu, berpotensi bergerak menuju persahabatan dan interaktivitas baik secara sosial dan bisnis, dengan demikian meningkatkan hubungan berkesinambungan. Social Bond menawarkan pelayanan kepada konsumennya melalui kegiatan sosial dalam rangka membangun hubungan jangka panjang. Social bond adalah upa yang dilakukan oleh tenaga penjualan melalui hubungan natar pribadi dan hubungan sosial.

\section{Behavioral Intention}

Niat berperilaku (behavioral intention) didefinisikan Mowen (2002) sebagai keinginan konsumen untuk berperilaku menurut cara tertentu dalam rangka memiliki, membuang dan menggunakan produk atau jasa. Jadi konsumen dapat membentuk keinginan untuk mencari informasi, memberitahukan orang lain tentang pengalamamannya dengan sebuah produk, membeli sebuah produk atau jasa tertentu, atau membuang produk dengan cara tertentu. Menurut Simamora (2003) niat berperilaku (behavior intention) adalah suatu proporsisi yang menghubungkan diri dengan tindakan yang akan datang. Menurut Kanuk (2003), niat berperilaku (behavior intention) adalah frekuensi pembelian atau proporsi pembelian total dari pembeli yang setia terhadap merek tertentu. Berdasarkan teori diatas, dapat disimpulkan bahwa behavioral intentions adalah suatu indikasi dari bagaimana orang bersedia untuk mencoba dan menanamkan 10 kepercayaaan pelanggan terhadap perusahaan sehingga menimbulkan kepuasan tersendiri.

\section{Metodologi Penelitian}

Penelitian ini merupakan penelitian kuantitatif (positivis). Objek 
penelitian ini adalah UMKM di Kota Malang dan Kota Batu yang memenuhi kriteria sebagai sampel penelitian. Penentuan sampel dalam penelitian ini diawali dengan menggunakan metode simple random sampling, yaitu pengambilan sampel yang dilakukansecara acak tanpa memperhatikan strata yang ada dalam populasi itu. Setelah terkumpul kemudian dilanjutkan dengan metode penggunaan kriteria (purposive sampling) untuk menentukan sample yang benar benar sesuai yang diharapkan. Adapun kriteria yang digunakan yaitu:

- UMKM yang bergerak pada sektor makanan dan minuman

- UMKM yang mendapat dana bantuan dari perbankan

- $\quad$ UMKM yang mendapat bantuan selama 2 kali berturut-turut

Sehingga didapatkan sampel penelitian yang terdiri dari 40 UMKM di Kota Malang dan 60 UMKM di Kota Batu. Metode analisis data selanjutnya yang digunakan dalam penelitian ini adalah metode Moderated Regresion Analysis (MRA).

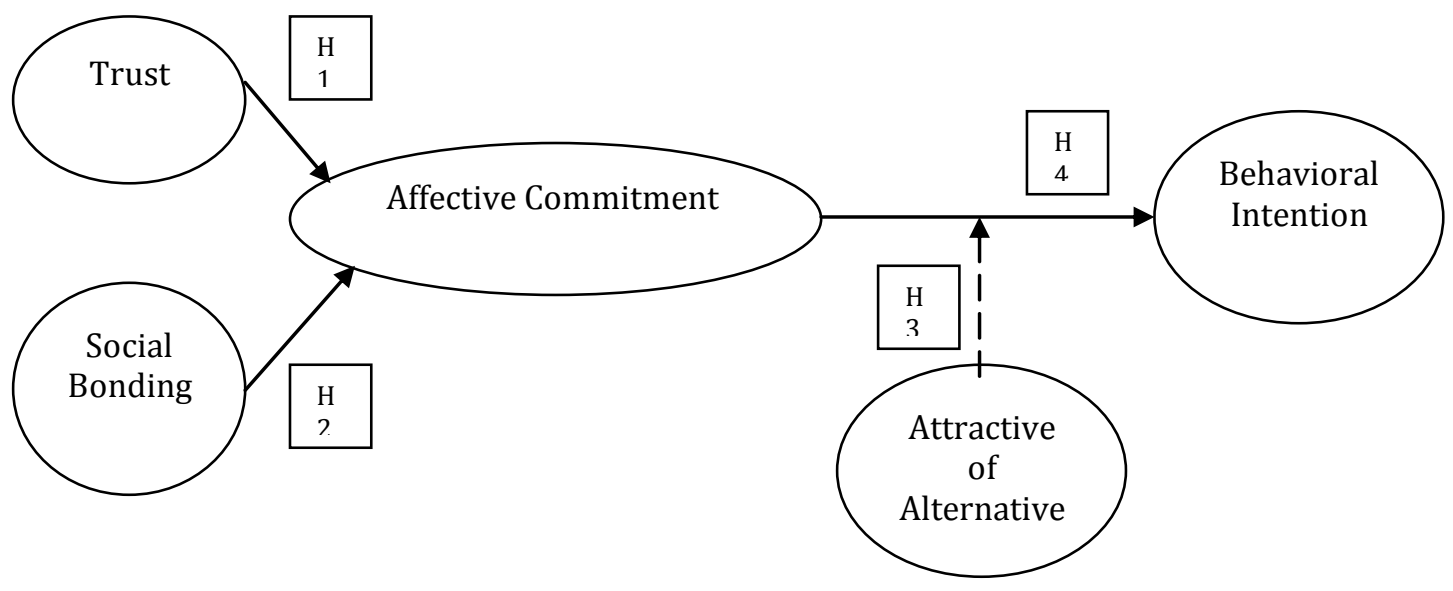

Gambar 1. Hipotesis Penelitian

\section{Hasil Penelitian}

\section{Deskripsi Karakteristik Responden}

Karakteristik responden pada penelitian ini dideskripsikan meliputi umur, tingkat pendidikan, jenis usaha dan penghasilan per-bulan. Responden sebanyak 100, hasil analisis karakteristik secara lengkap dapat dilihat pada Tabel 1. 
Tabel 1. Karakteristik Responden Berdasarkan Umur

\begin{tabular}{lcc}
\hline \multicolumn{1}{c}{ Umur } & Frekuensi & Persentase \\
\hline$<25$ tahun & 13 & $13 \%$ \\
$25-35$ tahun & 38 & $38 \%$ \\
$35-45$ tahun & 24 & $24 \%$ \\
$45-55$ tahun & 20 & $20 \%$ \\
$>55$ tahun & 5 & $5 \%$ \\
\hline Total & 100 & $100 \%$ \\
\hline
\end{tabular}

Tabel 2 Karakteristik Responden Berdasarkan Jenis Usaha

\begin{tabular}{ccc}
\hline Jenis Usaha & Frekuensi & Persentase \\
\hline Makanan Ringan & 32 & $32 \%$ \\
Makanan Berat & 68 & $68 \%$ \\
\hline Total & 100 & $100 \%$ \\
\hline
\end{tabular}

\section{Deskripsi Variabel Penelitian}

\section{Variabel Trust}

Variabel Trust terbentuk dari beberapa indikator yang meliputi: Kepercayaan (X1.1), Ketepatan Janji (X1.2), Pelayanan (X1.3), Kesediaan (X1.4), Kompetensi (X1.5), Integritas (X1.6), Responsif (X1.7). Indikatorindikator tersebut dilakukan pengukuran secara kuantitatif, dengan cara pemberian skor terhadap jawaban responden akan kuesioner yang telah dibagikan. Hasil dari jawaban responden dinterprtasikan pada Tabel 3.

Tabel 3 Deskripsi Variabel Trust (X1)

\begin{tabular}{|c|c|c|c|c|c|c|c|c|c|c|c|}
\hline \multicolumn{12}{|c|}{ Jawaban } \\
\hline \multirow[t]{2}{*}{ Indikator } & \multicolumn{2}{|c|}{ STS } & \multicolumn{2}{|c|}{ TS } & \multicolumn{2}{|c|}{ RR } & \multicolumn{2}{|c|}{$\mathbf{S}$} & \multicolumn{2}{|c|}{ SS } & \multirow[t]{2}{*}{ Rata-Rata } \\
\hline & $\mathbf{F}$ & $\%$ & $\mathbf{F}$ & $\%$ & $\mathbf{F}$ & $\%$ & $\mathbf{F}$ & $\%$ & $\mathbf{F}$ & $\%$ & \\
\hline $\mathrm{X} 1.1$ & 0 & $0 \%$ & 3 & $3 \%$ & 28 & $28 \%$ & 51 & $51 \%$ & 18 & $18 \%$ & 3,84 \\
\hline $\mathrm{X} 1.2$ & 0 & $0 \%$ & 1 & $1 \%$ & 26 & $26 \%$ & 56 & $56 \%$ & 17 & $17 \%$ & 3,89 \\
\hline $\mathrm{X} 1.3$ & 0 & $0 \%$ & 1 & $1 \%$ & 24 & $24 \%$ & 51 & $51 \%$ & 24 & $24 \%$ & 3,98 \\
\hline X1.4 & 0 & $0 \%$ & 1 & $1 \%$ & 20 & $20 \%$ & 53 & $53 \%$ & 26 & $26 \%$ & 4,04 \\
\hline $\mathrm{X} 1.5$ & 0 & $0 \%$ & 2 & $2 \%$ & 20 & $20 \%$ & 55 & $55 \%$ & 23 & $23 \%$ & 3,99 \\
\hline $\mathrm{X} 1.6$ & 0 & $0 \%$ & 2 & $2 \%$ & 19 & $19 \%$ & 59 & $59 \%$ & 20 & $20 \%$ & 3,97 \\
\hline $\mathrm{X} 1.7$ & 0 & $0 \%$ & 1 & $1 \%$ & 17 & $17 \%$ & 53 & $53 \%$ & 29 & $29 \%$ & 4,1 \\
\hline \multicolumn{11}{|c|}{ Trust (X1) } & 3,97 \\
\hline
\end{tabular}

\section{Variabel Social Bonding}

Variabel Social Bonding terbentuk dari tiga indikator yang terdiri dari:

IQTISHODUNA Vol. 16 (2), $2020 \mid 155$

http://ejournal.uin-malang.ac.id/index.php/ekonomi 
Perlakuan (X2.1), Komunikasi (X2.2), dan Kerjasama (X2.3). Indikatorindikator tersebut dilakukan pengukuran secara kuantitatif, dengan cara pemberian skor terhadap jawaban responden akan kuesioner yang telah dibagikan. Hasil dari jawaban responden dinterprtasikan pada Tabel 4.

Tabel 4. Deskripsi Variabel Social Bonding (X2)

\begin{tabular}{|c|c|c|c|c|c|c|c|c|c|c|c|}
\hline \multirow{3}{*}{ Indikator } & \multicolumn{10}{|c|}{ Jawaban } & \multirow{3}{*}{$\begin{array}{l}\text { Rata- } \\
\text { Rata }\end{array}$} \\
\hline & \multicolumn{2}{|c|}{ STS } & \multicolumn{2}{|c|}{ TS } & \multicolumn{2}{|c|}{$\mathbf{R R}$} & \multicolumn{2}{|c|}{$\mathbf{S}$} & \multicolumn{2}{|c|}{ SS } & \\
\hline & $\mathbf{F}$ & $\%$ & $\mathbf{F}$ & $\%$ & $\mathbf{F}$ & $\%$ & $\mathbf{F}$ & $\%$ & $\mathbf{F}$ & $\%$ & \\
\hline $\mathrm{X} 2.1$ & 0 & $0 \%$ & 0 & $0 \%$ & 26 & $26 \%$ & 45 & $45 \%$ & 29 & $29 \%$ & 4,03 \\
\hline $\mathrm{X} 2.2$ & 0 & $0 \%$ & 0 & $0 \%$ & 26 & $26 \%$ & 46 & $46 \%$ & 28 & $28 \%$ & 4,03 \\
\hline $\mathrm{X} 2.3$ & 0 & $0 \%$ & 0 & $0 \%$ & 23 & $23 \%$ & 57 & $57 \%$ & 20 & $20 \%$ & 3,99 \\
\hline \multicolumn{11}{|c|}{ Social Bonding (X2) } & 4,02 \\
\hline
\end{tabular}

\section{Variabel Affective commitment}

Variabel Affective commitment terdiri dari tiga indikator yang meliputi: keterikatan (Y1.1), Hubungan (Y1.2), Kepemilikan (Y1.3). Indikatorindikator tersebut dilakukan pengukuran secara kuantitatif, dengan cara pemberian skor terhadap jawaban responden akan kuesioner yang telah dibagikan. Hasil dari jawaban responden dinterprtasikan pada tabel berikut:

Tabel 5. Deskripsi Variabel Affective commitment (Y1)

\begin{tabular}{|c|c|c|c|c|c|c|c|c|c|c|c|}
\hline \multirow{3}{*}{ Indikator } & \multicolumn{10}{|c|}{ Jawaban } & \multirow{3}{*}{$\begin{array}{l}\text { Rata- } \\
\text { Rata }\end{array}$} \\
\hline & \multicolumn{2}{|c|}{ STS } & \multicolumn{2}{|c|}{ TS } & \multicolumn{2}{|c|}{ RR } & \multicolumn{2}{|c|}{$\mathbf{S}$} & \multicolumn{2}{|c|}{ SS } & \\
\hline & $\mathbf{F}$ & $\%$ & $\mathbf{F}$ & $\%$ & $\mathbf{F}$ & $\%$ & $\mathbf{F}$ & $\%$ & $\mathbf{F}$ & $\%$ & \\
\hline Y1.1 & 0 & $0 \%$ & 2 & $2 \%$ & 21 & $21 \%$ & 47 & $47 \%$ & 30 & $30 \%$ & 4,05 \\
\hline Y1.2 & 0 & $0 \%$ & 0 & $0 \%$ & 19 & $19 \%$ & 47 & $47 \%$ & 34 & $34 \%$ & 4,15 \\
\hline Y1.3 & 0 & $0 \%$ & 0 & $0 \%$ & 23 & $23 \%$ & 49 & $49 \%$ & 28 & $28 \%$ & 4,05 \\
\hline \multicolumn{11}{|c|}{ Affective commitment (Y1) } & 4,08 \\
\hline
\end{tabular}

\section{Variabel Behavioral Intention}

Variabel Behavioral Intention terbentuk dari beberapa indikator yang meliputi: Penggunaan jasa (Y2.1), Pertimbangan pertama (Y2.2), Peluang (Y2.3), pelayanan yang bagus (Y2.4), penggunaan layanan (Y2.5). Indikatorindikator tersebut dilakukan pengukuran secara kuantitatif, dengan cara pemberian skor terhadap jawaban responden akan kuesioner yang telah dibagikan. Hasil dari jawaban responden dinterprtasikan pada Tabel 6. 
Tabel 6 Deskripsi Variabel Behavioral Intention

\begin{tabular}{|c|c|c|c|c|c|c|c|c|c|c|c|}
\hline \multirow{3}{*}{ Indikator } & \multicolumn{10}{|c|}{ Jawaban } & \multirow{3}{*}{$\begin{array}{l}\text { Rata- } \\
\text { Rata }\end{array}$} \\
\hline & \multicolumn{2}{|c|}{ STS } & \multicolumn{2}{|c|}{ TS } & \multicolumn{2}{|c|}{$\mathbf{R R}$} & \multicolumn{2}{|c|}{$\mathbf{S}$} & \multicolumn{2}{|c|}{ SS } & \\
\hline & $\mathbf{F}$ & $\%$ & $\mathbf{F}$ & $\%$ & $\mathbf{F}$ & $\%$ & $\mathbf{F}$ & $\%$ & $\mathbf{F}$ & $\%$ & \\
\hline Y2.1 & 0 & $0 \%$ & 0 & $0 \%$ & 20 & $20 \%$ & 47 & $47 \%$ & 33 & $33 \%$ & 4,14 \\
\hline Y 2.2 & 0 & $0 \%$ & 0 & $0 \%$ & 24 & $24 \%$ & 51 & $51 \%$ & 25 & $25 \%$ & 4,01 \\
\hline Y 2.3 & 0 & $0 \%$ & 1 & $1 \%$ & 23 & $23 \%$ & 46 & $46 \%$ & 30 & $30 \%$ & 4,05 \\
\hline Y2.4 & 0 & $0 \%$ & 0 & $0 \%$ & 20 & $20 \%$ & 55 & $55 \%$ & 25 & $25 \%$ & 4,05 \\
\hline Y2.5 & 0 & $0 \%$ & 0 & $0 \%$ & 22 & $22 \%$ & 50 & $50 \%$ & 28 & $28 \%$ & 4,06 \\
\hline \multicolumn{11}{|c|}{ Behavioral Intention (Y2) } & 4,06 \\
\hline
\end{tabular}

\section{Variabel Attractive of Alternatives}

Variabel Attractive of Alternatives terdiri dari lima indikator yang secara menyeluruh membandingkan antara layanan perbankan dengan perusahan asing. Indikator-indikator tersebut dilakukan pengukuran secara kuantitatif, dengan cara pemberian skor terhadap jawaban responden akan kuesioner yang telah dibagikan. Hasil dari jawaban responden dinterprtasikan pada Tabel 7.

Tabel 7 Deskripsi Variabel Attractive of Alternatives (Z)

\begin{tabular}{|c|c|c|c|c|c|c|c|c|c|c|c|}
\hline \multirow{3}{*}{ Indikator } & \multicolumn{10}{|c|}{ Jawaban } & \multirow{3}{*}{$\begin{array}{l}\text { Rata- } \\
\text { Rata }\end{array}$} \\
\hline & \multicolumn{2}{|c|}{ STS } & \multicolumn{2}{|c|}{ TS } & \multicolumn{2}{|c|}{$\mathbf{R R}$} & \multicolumn{2}{|c|}{$\mathbf{S}$} & \multicolumn{2}{|c|}{ SS } & \\
\hline & $\mathbf{F}$ & $\%$ & $\mathbf{F}$ & $\%$ & $\mathbf{F}$ & $\%$ & $\mathbf{F}$ & $\%$ & $\mathbf{F}$ & $\%$ & \\
\hline Z.1 & 0 & $0 \%$ & 0 & $0 \%$ & 21 & $21 \%$ & 43 & $43 \%$ & 36 & $36 \%$ & 4,15 \\
\hline Z.2 & 0 & $0 \%$ & 1 & $1 \%$ & 22 & $22 \%$ & 47 & $47 \%$ & 30 & $30 \%$ & 4,06 \\
\hline Z.3 & 0 & $0 \%$ & 0 & $0 \%$ & 21 & $21 \%$ & 47 & $47 \%$ & 32 & $32 \%$ & 4,11 \\
\hline Z.4 & 0 & $0 \%$ & 0 & $0 \%$ & 23 & $23 \%$ & 48 & $48 \%$ & 29 & $29 \%$ & 4,06 \\
\hline Z.5 & 0 & $0 \%$ & 0 & $0 \%$ & 22 & $22 \%$ & 46 & $46 \%$ & 32 & $32 \%$ & 4,5 \\
\hline \multicolumn{11}{|c|}{ Attractive of Alternatives (Z) } & 4,17 \\
\hline
\end{tabular}

\section{Pembahasan}

\section{Hubungan antara trust dengan affective commitment}

Mengacu pada hasil uji pengaruh antara variabel trust dan affective commitment secara statistik didapatkan hasil bahwa hipotesis penelitian yang mengatakan trust berpengaruh positif terhadap affective commitment dapat diterima, sehingga dapat dikatakan bahwa kepercayaan yang dirasakan oleh UMKM Kota Malang dan Batu terhadap pelayanan perbankan sangat tinggi sehingga hal demikian akan memberikan dampak terhadap komitmen efektif yang lebih tinggi juga, sebagaimana diketahui bahwa kepercayaan 
yang berkepanjangan dan interaktif akan meningkatkan emosi dan memberikan komitmen afektif yang lebih besar. Hasil ini mendukung dari hasil penelitian sebelumnya yang dilakukan oleh penelitian DeWulf dan Odekerken-Schroeder, 2003; Fullerton, 2003; Garbarino dan Johnson, 1999), yang mana dalam penelitian mereka dinyatakan bahwa terdapat bubungan yang positif antara trust dan affective commitment. Jadi dapat dikatakan bahwa komitmen yang timbul adalah suatu proses yang berkesinambungan sebagai akibat dari terbentuknya sebuah kepercayaan UMKM Kota Malang dan Batu. Dalam hasil penelitian ini dapat mengindikasikan bahwa kepercayaan yang didapat oleh UMKM Kota Malang dan Batu akan dapat meningkatkan rasa komitmen.

\section{Hubungan social bonding dengan affective commitment}

Ikatan sosial (social bonding) merupakan hubungan yang diciptakan melalui keterlibatan berkelanjutan antara perwakilan dari kedua organisasi (Venetis dan Ghauri, 2004). Rodríguez dan Wilson (2002) menyatakan bahwa kekuatan ikatan sosial (social bond) yang dirasakan mempengaruhi kepercayaan pada mitra bisnis secara positif dan bahwa ikatan sosial dan kepercayaan akan memengaruhi komitmen pelanggan. Berdasarkan hasil pengujian pengaruh ikatan sosial (social bonding) terhadap affective commitment membuktikan bahwa hipotesis penelitian yang menyatakan social bonding berpengaruh positif terhadap affective commitment dapat diterima, sehingga dapat dikatakan bahwa ikatan sosial yang dibangun antara UMKM Kota Malang dan Batu dengan layanan perbankan melalui keterlibatannya secara berkelanjutan menyalurkan dampak terhadap komitmen yang efektif antara keduanya, sebagaimana diketahui Ikatan sosial memerlukan keakraban, kepercayaan diri yang dibangun melalui kedekatan hubungan Di sisi lain, hal terlihat dari tingginya tingkat kepercayaan yang dirasakan oleh UMKM Kota Malang dan Batu terhadap layanan perbankan sebagaimana pada pembahasan sebelumnya.

Pelanggan yang memiliki komitmen afektif yang kuat terus menggunakan layanan organisasi karena mereka menginginkannya. Hasil penelitian ini mendukung dari hasil penelitian sebelumnya yang dilakukan oleh penelitian Rodríguez dan Wilson (2002) yang menyatakan bahwa ikatan sosial (social bond) yang dirasakan mempengaruhi kepercayaan pada mitra bisnis secara positif dan bahwa ikatan sosial dan kepercayaan akan memengaruhi komitmen pelanggan. Jadi dapat dikatakan bahwa terciptanya komitmen efektif disebabkan adanya ikatan sosial diantara mitra bisnis yang dalam hal ini adalah UMKM Kota Malang dan Batu dan layanan perbankan. Dalam hasil penelitian ini juga menunjukan bahwa ikatan sosial yang terjalin 
diantara UMKM Kota Malang dan Batu dengan layanan perbankan akan dapat meningkatkan rasa komitmen efektif.

\section{Hubungan antara affective commitment dengan behavioral intention}

Hasil pengujian pengaruh affective commitmentterhadap Niat berperilaku (behavioral intention) menunjukan bahwa hipotesis penelitian yang menyatakan affective commitment berpengaruh positif terhadap behavioral intention dinyatakan diterima, sehingga dapat dikatakan bahwa komitmen efektif yang terbentuk karena adanya sebuah kepercayaan dan ikatan sosial yang ada pada UMKM Kota Malang dan Batu dengan layanan perbankan memberikan dampak terhadap niat perilaku yang akan dilakukan oeh UMKM Kota Malang dan Batu. Sebagaimana dikatakan bahwa niat perilaku pelanggan terhadap produk dan jasa merupakan hasil dari proses kepuasan yang dirasakan pelanggan terhadap produk dan jasa yang telah diberikan oleh penyedia produk dan jasa. Hasil penelitian ini mendukung dari hasil penelitian yang dilakukan oleh penelitian Bansal dan Taylor (1999) yang menemukan bahwa persepsi konsumen tentang kemudahan mereka beralih layanan berhubungan positif dengan niat dalam layanan keuangan. Jadi disimpulkan bahwa terciptanya komitmen efektif disebabkan adanya sebuah kepercayaan dan ikatan sosial diantara mitra bisnis akan memberikan dampak terhadap perilaku yang akan dilakukan oleh UMKM Kota Malang dan Batu

\section{Hubungan antara affective commitment, attractive of alternative dan behavioral intention}

Pritchard dkk. (1999) menunjukkan bahwa komitmen didorong oleh berbagai karakteristik psikologis yang melampaui tingkat keterikatan yang paling sederhana. Sementara dimensi komitmen afektif ditunjukkan, "keadaan psikologis yang menghubungkan pelanggan dengan mitra pemasaran yang didasarkan pada pada kedekatan hubungan" (Fullerton, 2011).

Hasil pengujian uji moderasi menunjukan bahwa variabel attractive of alternative mampu memperkuat hubungan yang dimiliki affective commitment dan behavioral intention, sehingga hipotesis dapat dinyatakan diterima. Adanya attractive of alternative ini membantu memperkuat dampak yang diberikan oleh komitmen efektif terhadap niat perilaku, sehingga hal ini dapat memberikan respon positif terhadap hubungan yang ada antar mitra bisnis, yang dalam hal ini UMKM Kota Malang dan layanan perbankan. Hasil ini mendukung dari hasil penelitian yang dilakukan sebelumnyaa oleh Aurier dan N'Goala (2010), Fullerton (2011), Bansal dan Taylor (1999) yang menyatakan adanya hubungan yang positif yang ada diantara tiga variabel.

IQTISHODUNA Vol. 16 (2), $2020 \mid 159$

http://ejournal.uin-malang.ac.id/index.php/ekonomi 
Jadi dapat dikatakan bahwa terciptanya niat perilaku yang positif yang disebabkan adanya komitmen efektif diantara mitra bisnis dapat diperkuat dengan adanya attractive af alternative yang dirasakan oleh UMKM Kota Malang dan Batu.

\section{Implikasi Penelitian dalam Pandangan Islam}

Berdasarkan beberapa Pembahasan yang telah diuraikan diatas mengindikasikan sangat pentingnya membangun sebuah kepercayaan dan ikatan sosial dalam bermitra (membangun usaha) sehingga akan menciptakan komitmen yang baik antar mitra yang meliputi meliputi rasa suka, keterikatan dan keterlibatan mewakili seperangkat perilaku, yang nantinya akan memberikan dukungan positif bagi hubungan berkelanjutan.

Penjelasan bermitra dalam islam diungkap dalam ayat al-Quran yang berbunyi:

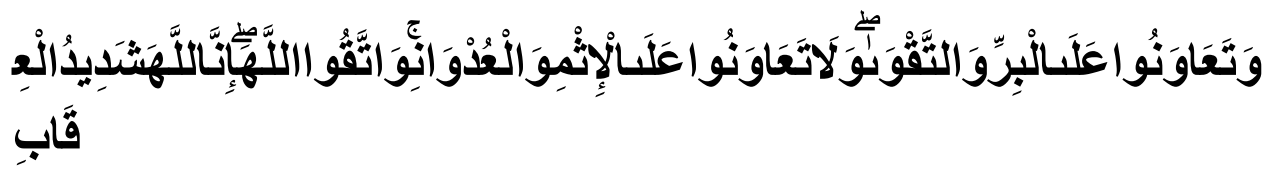

Artinya: "Dan tolong-menolonglah kamu dalam (mengerjakan) kebaikan dan takwa, dan jangan tolong-menolong dalam berbuat dosa dan pelanggaran." (Qs Al-Maidah [5]: 2.

Dalam tafsir almisbah diungkapkan bahwa ayat tersebut menunjukkan bahwa al-Qur'ân telah terlebih dahulu beberapa ratus tahun menganjurkan konsep kerjasama dalam kebaikan, dibanding semua undangundang positif yang ada. Artinya bahwa kerjasama untuk dalam hal menuju kebaikan telah diajarkan oleh agama islam semenjak turunnya surat ini. Islam menganjurkan serta memerintahkan untuk melakukan perbuatan baik bagi sesama, hal ini dimaksudkan agar manusia di dalam kehidupannya dapat bermanfaat bagi orang lain, memberikan nilai tambah bagi sesama serta mampu mengangkat derajadnya serta lingkungannya. Segala tindakan yang dilandasi dengan unsur ihsan dimaksudkan sebagai sebuah proses niat, sikap serta perilaku yang baik, sistem, serta transaksi yang baik untuk memberikan keuntungan bagi semuanya (Sutrisno, 2019). Dan oleh karenanya dalam Islam dikenal istilah musyarakah artinya adalah kerjasama (bermitra), musyarakah adalah sebuah produk yang dilahirkan oleh fiqh, yang mengatur akan sistematika dalam sebuah kerjasama (bermitra).

Musyarakah berasal dari kata syirkah. Syirkah menurut bahasa berarti al-ikhtilath yang artinya campur atau percampuran. maksud pencampuran disini adalah seseorang mencampurkan hartanya dengan harta orang lain 
sehingga tidak mungkin dibedakan. Musyarakah merupakan istilah yang sering dipakai dalam konteks skim pembiayaan syarikah. Istilah ini berkonotasi lebih terbatas dari pada istilah syirkah yang lebih umum digunakan dalam fiqih Islam, Musyarakah merupakan akad kerjasama diantara pemilik modal yang mencampurkan modal mereka dengan cara mencari keuntungan (Suhendi, 2007).

Dalam konsep Islam, musyarakah atau syirkah adalah bentuk umum dari usaha bagi hasil dimana dua orang atau lebih menyumbangkan dan manajemen pembiayaan usaha, dengan proporsi bisa sama atau tidak. Keuntungan dibagi sesuai kesepakatan antara para mitra, dan kerugian akan dibagikan menurut proporsi modal. Transaksi musyarakah dilandasi adanya keinginan para pihak yang berkerjasama untuk meningkatkan nilai asset yang mereka miliki secara bersama-sama dengan mendukung seluruh sumber daya yang ada. Allah SWT telah berfirman agar manusia saling tolong menolong dan bersama-sama berusaha untuk suatu tujuan yang baik , dengan kata lain Musyarakah adalah sebuah bentuk usaha atas dasar saling tolong-menolong antara sesama manusia dengan tujuan mendapatkan profit/laba, oleh sebab itu Prinsip dari musyarakah ini sangat dianjurkan dalam agama Islam.

Berdasarkan penjelasan tentang kerjasama (kemitraan) yang diajarkan dalam islam yang dikenal dengan istilah at-Ta'awun (tolong menolong), yang dalam hal ini dapat diinterpretasikan sebagai bantuan pembiayaan yang dilakukan oleh lembaga keuangan terhadap pelaku UMKM yang kemudian sistemnya diatur dalam ilmu fiqih islam menjadi istilah musyarakah yang berarti bahwa hubungan yang dibangun oleh kedua pihak antara pemodal yang dalam hal ini adalah lembaga keuangan (layanan perbankan) dan pengelola modal yaitu pelaku UMKM yang ada di Kita Malang dan Batu, hal tersebut membuktikan bahwa kegiatan yang dilakukan oleh pelaku UMKM kota Malang dan Batu dengan layanan perbankan adalah merupakan kegiatan yang diatur secara detail dalam agama islam dalam surat al-Maidah ayat 2 diatas yang mendukung keberadaan prinsip dari pada musyarakah, dimana setiap parthner dalam bisnis haruslah mempunyai ahlak yang baik pada saat melakukan usaha bisnisnya. Akhlak yang baik tersebut dapat diinterpretasikan sebagai komitmen yang dibangun antara kedua pihak untuk dapat menciptakan rasa kepercayaan (trust) dan ikatan sosial (social bonding) yang baik, sehinga dapat dikatakan sah dan baik menurut syariat atau dalam penelitian ini dikatakan agar dapat membangun hubungan yang berkelanjutan. 


\section{Kesimpulan}

Hasil uji pengaruh antara variabel trust dan affective commitment menujukkan bahwa kepercayaan (trust) berpengaruh positif dan signifikan terhadap komitmen efektif (affective commitment). Pengaruh ikatan sosial (social bonding) terhadap affective commitment membuktikan bahwa social bonding berpengaruh positif dan signifikan terhadap affective commitment. Pengaruh affective commitment terhadap Niat berperilaku (behavioral intention) menunjukan affective commitment berpengaruh positif dan signifikan terhadap behavioral intention. Uji moderasi dengan menggunakan Moderated Regresion Analysis (MRA), yang menguji variabel attractive of alternative dalam perannya terhadap hubungan yang ada pada affective commitment dan Niat berperilaku (behavioral intention), secara statistik menunjukan bahwa variabel attractive of alternative mampu memperkuat hubungan yang dimiliki affective commitment dan behavioral intention.

\section{Daftar Pustaka}

Aurier, P., \& N'Goala, G. (2010). The differing and mediating roles of trust and relationship commitment in service relationship maintenance and development. Journal of the Academy of Marketing Science, 38(3), 303325.

Badan Pusat Statistik. (2017). Hasil Pendaftaran (Listing) Usaha/Perusahaan Sensus Ekonomi 2016. Hasil Pendaftaran (Listing). Usaha/Perusahaan Sensus Ekonomi 2016 No. 35/05/35/Th. XV, 24 Mei 2017.

Badulescu, D. (2012). SMEs Relationship Banking: Length, Loyalty, Trust. Do SMEs get something in Return?. World Academy of Science, Engineering and Technology . International Journal of Economics and Management Engineering, 6(6).

Basir S \& Prajawati, M. I. (2016). Kajian Penyusunan Model Pengembangan Ekonomi Koperasi/UMKM yang Berbasis Syariah untuk Meingkatkan Produktivitas Ekonomi. Laporan Tidak Dipublikasikan

Bansal, H. S., Irving, P. G., \& Taylor, S. F. (2004). A three-component model of customer to service providers. Journal of the Academy of Marketing Science, 32(3), 234-250.

Beck, T., Cull, R., \& Jerome, A. (2005). Bank privatization and performance: Empirical evidence from Nigeria. Journal of Banking \& Finance, 29(8), 2355-2379.

162 | IQTISHODUNA Vol. 16 (2), 2020 http://ejournal.uin-malang.ac.id/index.php/ekonomi 
Bell, S. J., \& Eisingerich, A. B. (2007). The paradox of customer education: customer expertise and loyalty in the financial services industry. European Journal of Marketing, 41(5/6), 466-486.

Ca'novas, Gine's Herna'ndez and Pedro Martı́nez-Solano. (2010). Relationship lending and SME financing in the continental European bank-based system. Small Bus Econ (2010) 34:465-482 DOI 10.1007/s11187-008-9129-7

Cater, T., \& Cater, B. (2010). Product and relationship quality influence on customer commitment and loyalty in B2B manufacturing relationships. Industrial Marketing Management, 39(8), 1321-1333.

Cater, B., \& Zabkar, V. (2009). Antecedents and consequences of commitment in marketing research services: The client's perspective. Industrial Marketing Management, 38(7), 785-797.

Cater, B and Zabkar, V. (2009). Antecedents and Consequences of Commitment in Marketing Research Services: The Client's Perspective. Industrial Marketing Management, 38, 785-797.

Claro, D. P., Borin, P. \& Zylbersztajn, D. (2005). “Relationship marketing strategies: when buyer and supplier follow different strategies to achieve performance", Brazilian Administration Review, 2(2), 17-34.

Coote, L. V., Forrest, E. J., \& Tam, T. W. (2003). An investigation into commitment in non-Western industrial marketing relationships. Industrial Marketing Management, 32(7), 595-604.

Cooper, Donald R and Pamela S Schindler. (2003). Business Research Methods. McGraw-Hill.Irwin. Jan1.2003.

De la Torre,Augusto de la., María Soledad Martínez., Pería, Sergio L. Schmukler. (2010). Bank involvement with SMEs: Beyond relationship lending. Journal of Banking \& Finance, 34 (2010) 2280-2293.

Dogarawa, B. A. (2011). Chronology of banking reforms in Nigeria. Journal of Financial Regulation and Compliance, 19(4), 370-382.

Doole, I. \& Lowe, R. (2012). International Marketing Strategy, Analysis, Development and Implementation, 6th edition, Cengage: South Western

Dhliwayo. (2014). Role of The Banking Sector In Promoting Growth \& Development Of Small And Medium Enterprises. The 2nd Sme Banking \& Microfinance Summit 2014 March 2014.

Egan. J. (2005). Relationship Marketing Exploring Relational Strategis in

IQTISHODUNA Vol. 16 (2), $2020 \mid 163$

http://ejournal.uin-malang.ac.id/index.php/ekonomi 
Marketing. Second editon. New Jersey : Pearson Education.

Firmansyah, F \& Prajawati, M.I (2016). Strategi Kemitraan Perbankan Syariah dengan UMKM dalam Rangka Meningkatkan Kinerja UMKM di Kota Malang. Laporan Penelitian Fakultas Ekonomi, Tidak Dipublikasikan.

Fullerton, G. (2005a). How commitment both enables and undermines marketing relationships. European Journal of Marketing, 39(11/12), 1372-1388.

Fullerton, G. (2005b). The service quality-loyalty relationship in retail services: does commitment matter? Journal of Retailing and Consumer Services, 12(2), 99-111.

Fullerton, G. (2011). Creating advocates: the roles of satisfaction, trust and commitment. Journal of Retailing and Consumer Services, 18(1), 92100.

Fullerton, G. (2014). The moderating effect of normative commitment on the service quality-customer retention relationship. European Journal of Marketing, 48(3/4), 12-12.

Garbarino, E., \& Johnson, M. S., (1999), "The different roles of satisfaction, trust and commitment in customer relationships. Journal of Marketing, 63(2).

Ghozali, I. (2013). Aplikasi Analisis Multivariate dengan Program IBM Spss, Semarang. Universitas Diponegoro.

Gilliland, D. I., \& Bello, D. C. (2002). Two sides to attitudinal commitment: the effect of calculative and loyalty commitment on enforcement mechanisms in distribution channels. Journal of the Academy of Marketing Science, 30(1), 24-43.

Herdian, Gina dan Widyastuti. (2013). Pengaruh Relationship Marketing Terhadap Loyalitas Pelanggan Pada Nasabah Bank BTPN KCP Sepanjang". Jurnal Ilmu Manajemen, 1(2).

Hennig-Thurau, T. (2000). Relationship Quality and Customer Retention through Strategic Communication of Customer Skills. Journal of Marketing Management, 16(1-3), 55-79.

Hutchinson, D., Wellington, W. J., Saad, M., \& Cox, P. (2011). Refining valuebased differentiation in business relationships: A study of the higher order relationship building blocks that influence behavioural intentions. Industrial Marketing Management, 40(3), 465-478.

164 | IQTISHODUNA Vol. 16 (2), 2020

http://ejournal.uin-malang.ac.id/index.php/ekonomi 
Jones, T., Fox, G. L., Taylor, S. F., \& Fabrigar, L. R. (2010). Service customer commitment and response. Journal of Services Marketing, 24(1), 16-28.

Keegan, Sandra Motiarty, Tom Duncan. (1995). Marketing. New Jersey : Prentice Hall

Keh, H. T., \& Xie, Y. (2009). Corporate reputation and customer behavioral intentions: The roles of trust, identification and commitment. Industrial Marketing Management, 38(7), 732-742.

Lakip Kota Malang. (2016). Pemerintah Kota Malang.

Lang, Frank., Simone Signore and Salome Gvetadz. (2016). The role of cooperative banks and smaller institutions for the financing of SMEs and small midcaps in Europe. Research \& Market Analysis Frank Lang with contributions from Simone Signore Salome Gvetadze. Working Paper 2016/36.

Lin, L. Y., \& Lu C. Y., (2010). The influence of corporate image, relationship marketing, and trust on purchase intention: the moderating effect of word-of-mouth. Tourism Review, 65(3), 16-34.

Malhotra, N. K. (2009). Riset Pemasaran. Edisi Keempat. Jakarta. PT Indeks.

McKnight, D. H. \& Chervan, N.L. (2002). What trust means in e-commerce customer relationships: an interdisciplinary conceptual typology. International Journal of Electronic Commerce, 6(2), 35-53.

Morgan, R. M., \& Hunt, S. D. (1994). The commitment-trust theory of relationship marketing. Journal of Marketing, 58(3), 20-38.

Menon, K. and O'Connor, A. (2007) Building customers' affective commitment towards retail banks: the role of CRM in each 'moment of truth'. Journal of Financial Services Marketing, 12(2), 157-168

Mowen. John dan Jerry. C. Olson (2002). Perilaku Konsumen. Terjemahan: Lina Salim. Jakarta: Erlangga

Ojeme, M., Robson, A. and Coates, N. (2018) Investigating the Nigerian Small and Medium Enterprises (SME)-banking long term relationship building. International Journal of Bank marketing, 36(1), 89-110. https://doi.org/10.1108/IJBM-07-2016-0097

Prager, R., Wolken, J. (2008). The evolving relationship between community banks and small businesses: Evidence from the surveys of small business finances. Federal Reserve Board Finance and Economics Discussion Series 2008-60. 
Basir. S, Maretha Ika Prajawati

Pritchard, M. P., Havitz, M. E., \& Howard, D. R. (1999). Analyzing the commitment-loyalty link in service contexts. Journal of the Academy of Marketing Science, 27(3), 333-348.

Shani, David and Sujana Chalasani. 1992. Exploiting Niches Using Relationship Marketing. Journal of Consumer Marketing 9(3):3342 - December 1992. DOI: 10.1108/07363769210035215

Suhendi, H. (2007). Fiqih Muamalah. Jakarta: PT. Raja Grafindo Persada.

Zethaml, Valarie, Mary Jo Bitner, and Dwayne D Gremler. (2013). Service Marketing. Mc Graw Hill International Edition.

Zeithaml, V. Parasuraman, A. and L. Berry L. (1985). Problems and Strategies in Services Marketing. Jurnal of Marketing,49. (Spring). 